International Journal of Engineering \& Technology, $7(3.1)(2018) 191-193$
International Journal of Engineering \& Technology
Website www.sciencepubco.com/index.php/IJET
Research paper

\title{
Database Management using Embedded System and CAD
}

\author{
Anitha Mary $\mathbf{M}^{1}$, Bharathy $\mathbf{R}^{2}$, Jhanani Shree $\mathbf{U}^{3^{*}}$, Richard Jebasingh $\mathbf{S}^{4}$ \\ ${ }^{1,2,3,4}$ Assistant Professor, Department of Electronics and Communication Engineering, Rajalakshmi Engineering College, Chennai, India. \\ *Corresponding author E-mail: jananishree.u@ rajalakshmi.edu.in
}

\begin{abstract}
An aim of this paper is to use Radio Frequency Identification (RFID) technology in facilitating efficient file management system. RFID is an abbreviation of radio frequency identification, RFID was poised to take off and become a standard piece of library technology. An RFID transmitter is also needed to capture the radio frequency signal from the tag for turn out to be giving out by the RFID reader. Therefore RFID has been referred to as "a non-contact method of using radio frequency electromagnetic waves for communication between two remote entities". An Objective of this paper is to design 3D modeling of file rack using Creo software, manage the files using RFID tag, read the files from RFID using microcontroller through embedded code and to display the files using 16x2 Liquid Crystal Display and 4x4 keypad. The position of the files in the rack will be identified using Light Emitting Diode.
\end{abstract}

Keywords: Radio Frequency Identification, Liquid Crystal Display, and Light Emitting Diode and Creo Software.

\section{Introduction}

An RFID system composed into three parts: a minuscule chip on each consumer item that stores a unique product identifier, an RFID reader and a computer system attached to the reader have access to the database. The database contains product information, origin and manufacturing product information. Assigning a tag to a product encloses its location, rate and place of sale and progress. The RFID reader transforms the data captured from the tags into another application. In library RFID systems the reader acts as the important element for getting the information from the tag.

\section{File Management System}

File Management system includes design 3D modeling of file rack using creo software, manage the files using RFID tag and read the files from RFID using microcontroller through embedded code. The files are displayed using 16x2 LCD and 4x4 keypad. The position of the files is displayed in the rack using LED. Availability and non-availability of the files will be displayed.

\subsection{D modeling of File Rack using Creo Software}

PTC Creo software is one of the most widely used CAD software programs in the world today. The PTC Creo by creating two simple parts, assembling them and creating drawings. Creo software for providing a divergent set of capabilities for a user role within product expansion. 3D modeling of file rack is designed based on the Extrude tool. Design features often follow a geometrically predictable pattern and parts are patterned in parametric design by referencing either construction dimensions or existing patterns.

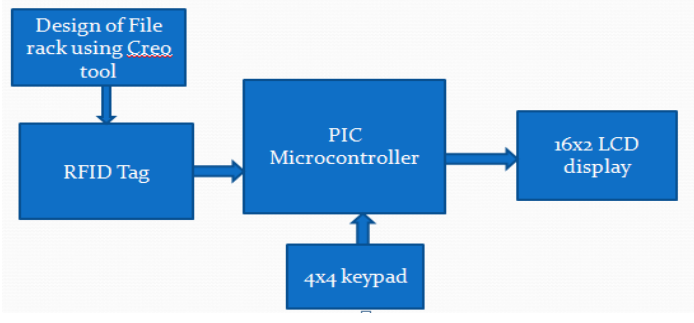

Fig. 1: Block Diagram

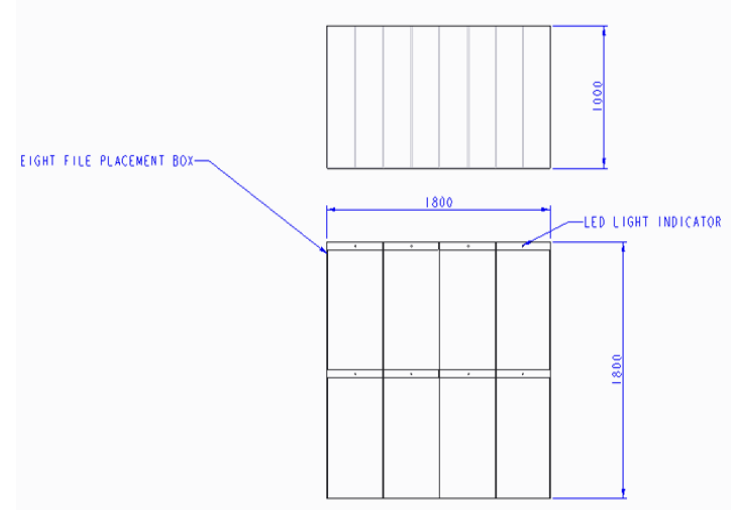

Fig. 2: Dimensions of file rack

\subsection{File Management using RFID and PIC Microcon- troller}

A. RFID Reader Module: RFID Reader Module This is a low frequency (125 Khz) RFID reader with serial output with at range of $8-12 \mathrm{~cm}$. It is a unit with built in transmitter and can be directly connected to the PC using RS232 protocol. There are loads of 
types of RFID and at the uppermost level of categorization these can be divided into two classes: energetic and reactive device. Energetic tags require a power source and either need a connection to powered communications or have a limited lifetime defined by the energy stored in an incorporated array, balanced against the number of read operations that will be performed on the tag. RFID is used mainly because the tags don't require arrays or protection. The tags have an eventual equipped life and are minute enough to fit into a practical bounding agent label. RFID system is comprised of three basic mechanisms: reader, antenna and chip less tag. The antenna illuminates the reader area and induces currents on the metallic tags. The induced currents reradiate the scattered fields, which will be processed in the reader for decoding the IDs of the tags. The RFID tag reader is held responsible for giving power and communicates with a tag. The tag transmitter captures energy and transfers the tag's ID (the tag's chip coordinates this process). RFID tag is attached to each file to indicate the file name.

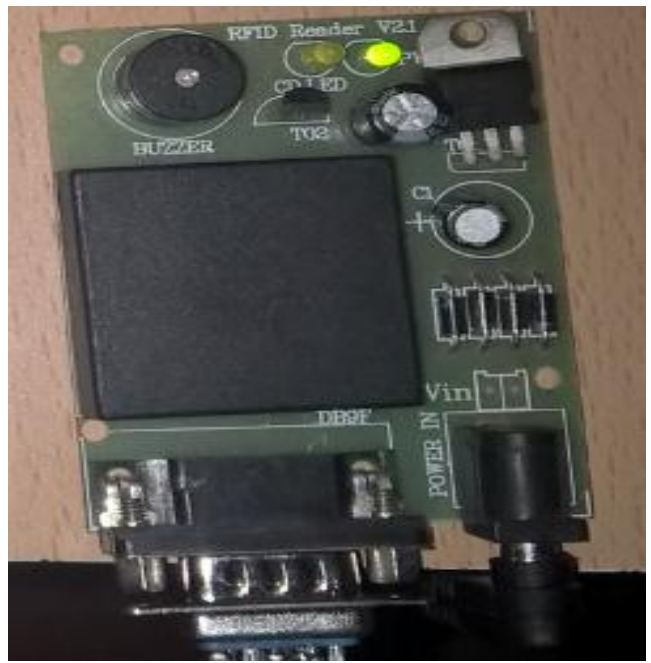

Fig. 3: RFID Reader Module

There are numerous types of tags that are used to power the tag and these are referred to as energetic tags. Those that don't include an on board array have power beamed to them by the reader and are called submissive tags. RFID tags can hold many kinds of information about the objects they are attached to, including serial numbers, time stamps and pattern commands. The presence of an internal power source enables energetic tags to possess greater read ranges than submissive tags. Energetic tag ranges are measured in meters rather than inches or feet as in the case with submissive tags. The increased range enables as active RFID system to employ fewer reader transmitters and read a larger number of tags from a given position than a submissive system. The tag information is stored in a memory. The RFID tag includes either eternal or programmable logic for processing the communication and sensor figures, respectively. PIC 16F877/874 controller is interfaced with RFID reader to manage the files.16x2 LCD is used to display the files which are available in the rack through RFID tag. The LCD rational alphanumeric dot matrix displays is capable of displaying the different characters and symbols. In this paper, Six files are managed and the availability of these files are shown in LCD.

\section{Results and Discussion}

3D modeling of file rack is designed with Creo software. The file can be placed in the rack with the serial number assigned. The file can be searched by using the number saved in the controller. Library is created with the file number and it will be displayed in the LCD display.

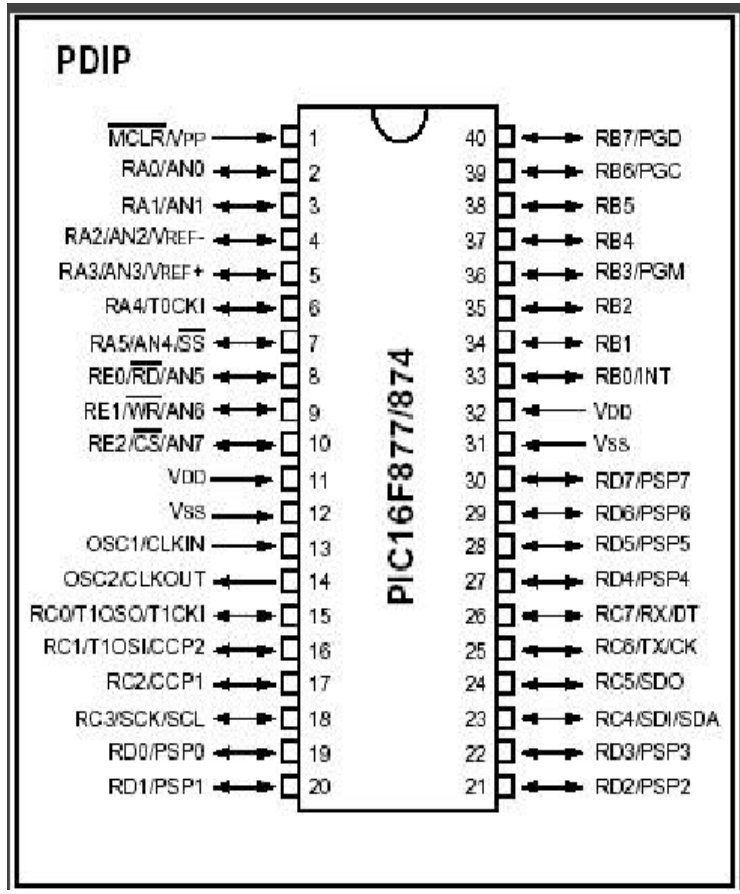

Fig. 4: PIC Microcontroller

\subsection{D modeling of Files Rack}

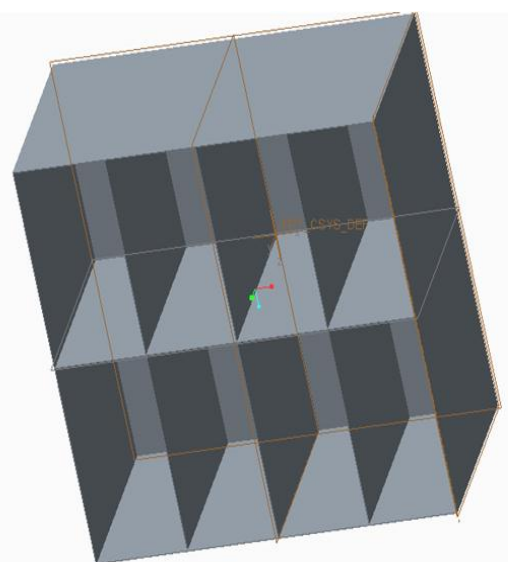

Fig. 5: 3D modeling of File rack

\subsection{Management of Files Using RFID Tag}

RFID tag is attached to each file and the file is identified using the tag through embedded code using Microcontroller.

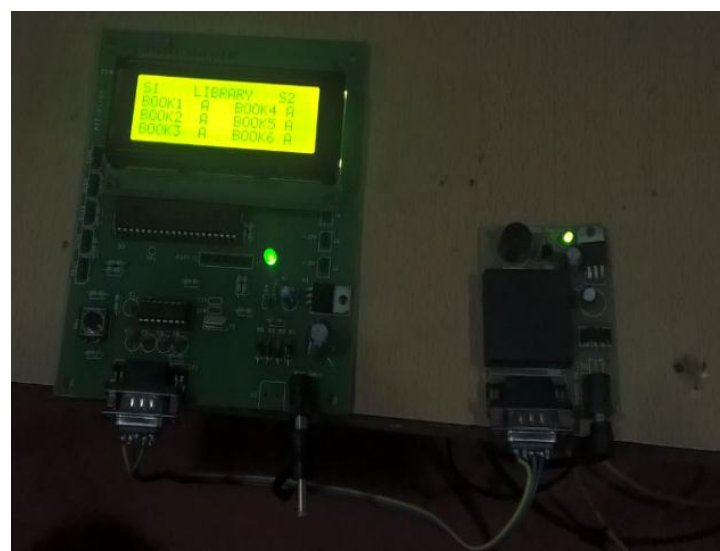

Fig. 6: Interfacing of RFID Reader with PIC Microcontroller 
To indicate the file in the rack with the help of RFID tag by using LED placed in the each rack. PIC microcontroller is connected to RFID tag and the LCD display for identifying the files.

\subsection{Implementation of Files using Microcontroller, key- pad and LCD Display}

The files which are available in the rack are identified and the availability of files is displayed in 16x2 LCD.4x4 keypad is used to get the files from rack. The availability of files is indicated by LED.

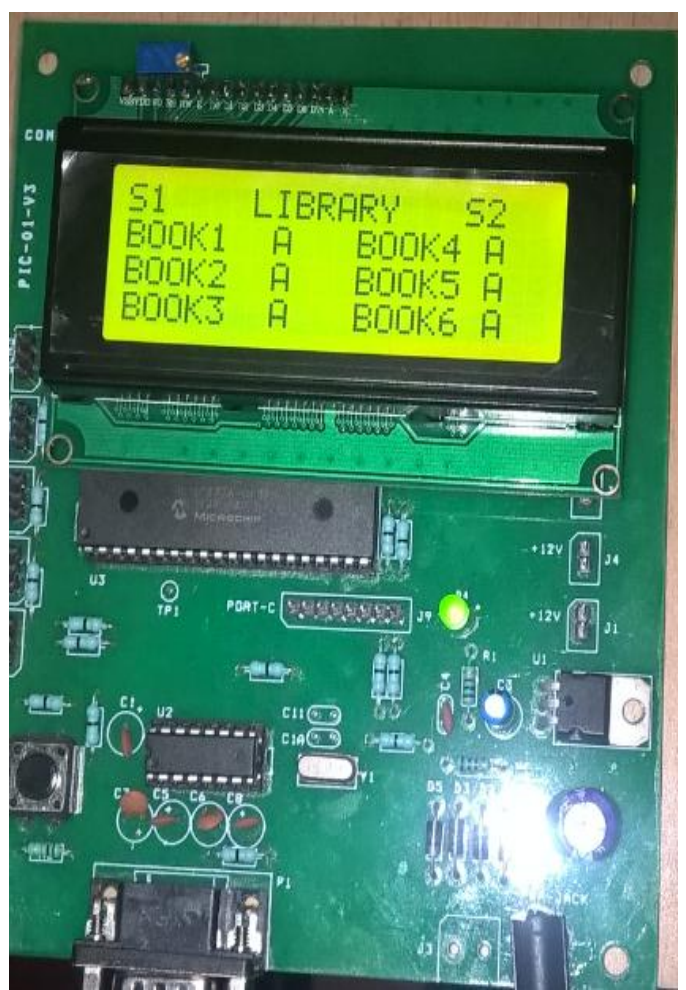

Fig. 7: Appearance of files using LCD

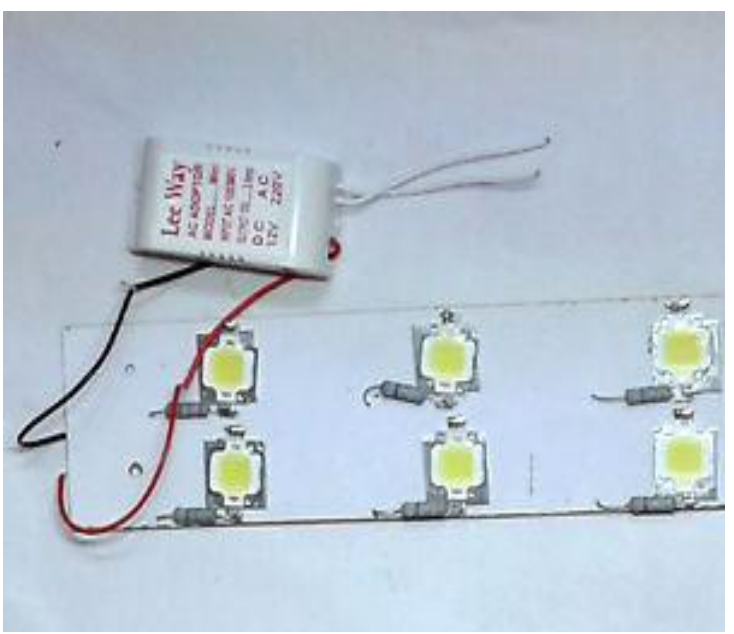

Fig. 8: LED Bulb Indicator

\section{Conclusion}

In this paper, RFID is recognized as the ideal technology for managing the files. Efficient file management system is implemented using Microcontroller. Manual searching of files will be avoided using this project. Time consuming is a best factor of this paper.

\section{References}

[1] Howard, L. \& Anderson, M. (2007), RFID technology in the library environment," Georgia Library Quarterly:44,http://digitalcommons.kennesaw.edu/glq/vol44/issI/6 [accessed 20 October 2014].

[2] Kobsa, A, Nithyanand, R., Tsudik, G \& Uzun, E. (2011), Usability of Display-Equipped RFID Tags for Security Purposes, In Computer Security-ESORICS, Berlin: Springer, pp. 434-451

[3] Automatic Identification and Data Collection (AIDC) Archived May 5, 2016, at the Wayback Machine.

[4] G. Ramprabu, J. Saranya, R.Swathi, (2017), "Stereo Audio Streaming Using Li-Fi Technology", International Journal of Computer Application (2250-1797), Volume 7- No.2, March - April 2017, pp.44-48.

[5] G. Ramprabu, S. Nagarajan, "Design and Analysis of Novel Modified Cross Layer Controller for WMSN", Indian Journal of Science and Technology, Vol 8(5), March 2015, pp.438-444. 